\title{
Study on the Application of the System of Pretrial Meetings
}

\author{
Haojun Jiang \\ Wuhan University of Technology \\ Wuhan, China
}

\begin{abstract}
As an important part of pretrial procedure preparation, pretrial meeting is very important for improving litigation efficiency and guaranteeing procedural and substantive justice. From a functional point of view, pre-trial meetings can decide procedural items, exclude illegal evidence, sort out evidence and clarify the focus of the dispute. However, there are still many problems in the application of the system of pre-court meeting, such as the scope of application of precourt meeting, participants, legal effect, and the exclusion of illegal evidence. In this case, the study of the pre-trial meeting can make legislators have a clear expectation of this system, not only can effectively improve the efficiency of litigation, save judicial resources, but also help to improve the pre-trial meeting of the judicial system. As an important part of judicial activities, the pre-trial meeting is not only a preparatory part of the trial, but also has its own relative independence. Pretrial meetings have many functions, including understanding facts, identifying problems, enriching trials, and promoting reconciliation and mediation. The empirical study of the precourt meeting shows that the active research of the local court provides rich practical experience for the application of the pre-court meeting. Starting from the concept and characteristics of the pre-trial meeting, this paper makes a comprehensive study of the application of the system of pretrial meeting in China, analyzes the shortcomings of the application of the system of pre-trial meeting in China, analyzes the causes of these problems from the legal point of view, and puts forward some suggestions for improvement.
\end{abstract}

Keywords-criminal proceedings; pretrial meetings; illegal evidence; preparatory procedures

\section{INTRODUCTION}

"What is a pre-court meeting? In the Criminal Procedure Law, a pre-court meeting means that, in order to avoid a long trial, a judge may, on the basis of his or her powers or on the application of both the prosecutor and the defender, convene the public prosecutor, the party concerned, the defender and the agent ad litem when necessary. In court, we should make necessary preparations for relevant issues in court hearing. " In the Interpretation of the Supreme People's Court, this system has been further elaborated, and under what circumstances can this procedure be initiated, which not only enriches and perfects the content of the pre-trial meeting, but also makes the application of the pre-trial meeting more operable. However, this system is also applicable. After only four years of implementation, the regulations are not yet ripe.
How to improve and develop the pre-court meeting will be an important issue for us to consider together.

\section{CHARACTERISTICS OF PRETRIAL CONFERENCE SYSTEM IN CHINA}

In China's judicial practice, the system of pre-court meeting is widely used, "pre-court meeting as a preparatory procedure before the case enters the entity, the purpose is to ensure the realization of the principle of centralized trial." However, many judges are not fully aware of the pre-trial meeting. For example, some judges have too high expectations of the pre-trial meeting, not only to advocate for the judge's jurisdiction in the process of the pre-trial meeting, but also to cross-examine the evidence at the pre-trial meeting stage, which unduly expands the merits of the pretrial meeting. Therefore, it is particularly important to distinguish the characteristics of pretrial meetings.

\section{A. Non Public}

According to the provisions of the criminal procedure law, it is not difficult to find that the pretrial meetings are characterized by non-openness. In the course of hearing a case, in order to understand the situation, the judge can call the prosecution and the defense to inquire about the legitimacy of the evidence, evasion and witness issues before the formal hearing. "In order to proceed with a sustained, planned and expeditious public hearing, the Court may, if it deems it necessary, hear the views of the defendant's defenders and prosecutors and decide before the first public hearing to refer the case to the pre-trial consolidation process." The principle of trial openness in the Criminal Procedure Law is the first principle throughout the trial stage, but this principle can only be applied in the trial stage of the court, so the principle does not apply because the pre-trial meeting is not a part of the formal trial, so that the pre-trial meeting is a non-public one. Although the procedure is not public, it has certain significance for judges to understand the case and improve the efficiency of litigation. In this way, however, the system could easily escape public scrutiny and evolve into an internal trial, not only worrying about the impartiality of justice.

\section{B. Non Antagonistic}

In the Interpretation made by the Supreme People's Court, we can find that the defendant has no right to apply for a pre- 
trial meeting, and can only participate in the pre-trial meeting at the notice of the judge. In practice, the defendant will often absent from the pre-trial meeting for various reasons, if the defendant is absent from the criminal trial process. Preface, then, lacks the main participants. "Negotiation is impossible if the procedure is not divided into opposites" and the purpose of the pre-trial meeting is simply to listen to and understand the case and procedural issues. There is no thought to allow the prosecution and the defense to engage in a pre-trial debate. The whole pre-trial meeting is judgecentered. Preparatory procedure and the debate between the prosecution and the defense can only be conducted in formal court proceedings, so non-confrontation is also an important feature of the pre-court meeting.

\section{Non Refereeing}

According to the general provisions of the new Criminal Procedure Law, we find that the judicial power belongs to the people's court, and the people's court must exercise the judicial power in court in strict accordance with the provisions of the Criminal Procedure Law, so the pre-court meeting will not have the procedure of hearing opinions and understanding the situation before the trial and the function of court trial. "The pre-trial meeting is a consultation procedure set up for the smooth and efficient conduct of the trial, and it is the preparatory and preparatory procedure for the trial, not the trial itself." At the same time, the law does not stipulate the validity of the agreement reached between the prosecution and the defense in the pre-trial meeting on certain issues, so it does not have the adjudicative nature. In the actual implementation process, many court judges confuse the boundaries between the trial and the pre-trial meeting, even in the pre-trial meeting has been determined how to make a decision in court, greatly affecting judicial justice, so the non-adjudicative characteristics of the pre-trial meeting is also a case that each judge should bear in mind and comply with. The guidelines are of great significance for ensuring fair and fair judicial procedures.

\section{ON THE SySTEM OF PRETRIAL CONFERENCE IN CHINA}

\section{A. The Scope of Application of Pretrial Conference in China}

The author finds that there are many problems in the scope of application of our country's pretrial meeting system by studying the current situation of our country's pretrial meeting system. On the one hand, the question is whether a pre-trial meeting can be held when a case is subject to summary procedure. There are two opinions in academic circles. The first is that no pre-trial meeting should be held when the case is subject to summary procedure, because the facts of the cases are clear. If we call for pre session meetings, we will easily waste judicial resources. The second is that the application of summary proceedings in cases cannot be completely excluded from the application of pretrial meetings, because the application of summary proceedings in cases may also have jurisdiction and avoidance issues, if the application of pre-trial meetings is completely excluded, it may not be conducive to the protection of the rights and interests of the accused.

On the other hand, the question is whether the pretrial meeting can be applied when the defendant does not entrust a defence counsel. Academia also has two opinions on this. The first is that when the defendant has not entrusted a lawyer, he should not hold a pretrial meeting because the defendant lacks the relevant legal knowledge and cannot fully understand some procedural issues. Even if the pretrial meeting is held, it is difficult to achieve its own purpose, so he should be the defendant. When a lawyer is not appointed, he shall not call for a pretrial session. The second view objected to this, because if the defendant was not allowed to participate in the pre-trial meeting because he had not entrusted a lawyer, it would damage the rights and interests of the defendant, and would not be conducive to the development of litigation activities.

Another problem is that the Criminal Procedure Law stipulates that the pre-trial meeting should be held in the first instance procedure, and does not stipulate whether the pretrial meeting can be held in the second instance procedure, so whether the pre-trial meeting can be applied in the second instance procedure or not, there have been two views in academic circles. One view is that the pre-trial meeting should be strictly in accordance with the law and only in the first instance procedure. Before the meeting, the second view holds that even if the law does not specify it, pre-trial meetings should be held in accordance with the original intention of the law when problems arise in the second instance proceedings.

\section{B. Subject Matter of Attending Pretrial Meetings}

The participants in pretrial meetings are also controversial. "Although the pre-court meeting mainly deals with procedural matters, procedural issues still have a certain impact on the defendant, so the defendant should attend the pre-court meeting." The core of criminal prosecution is to investigate the criminal responsibility of the defendant, to convict and sentencing the defendant. After the beginning of criminal proceedings, the defendant's property, personal freedom, and even life may be deprived. The court's final judgment has the most direct interest with the defendant. However, in the interpretation made by the Supreme People's Court, we find that the defendant does not have the right to apply for a pre-trial meeting, and can participate in the pretrial meeting only if notified by the judge, while the defendant and the defendant are only participants in the pretrial meeting and have no right to start the pre-trial meeting. If the defendant fails to attend the pre-trial meeting, the defendant's right to sue is entirely in the hands of the defender and the prosecutor. Since the law does not stipulate whether the validity of the agreement reached by the defendant in the pre-trial meeting can be assumed by the defendant, then the defendant's right to sue is heated up in the pre-trial meeting. During the day's discussion, the defendant knew nothing about the contents of the discussion and could only swallow the consequences of the discussion by himself. "It can be found that the relevant pretrial meetings in China have highlighted the strong sense of 
authority." Moreover, if the defendant has not entrusted the defendant or is unwilling to entrust the defendant, then the defendant in the pre-trial meeting, the main subject of litigation, is difficult to judge their litigation rights, which is unfair to the defendant, and the legitimacy of the evidence obtained by the judge is also difficult to believe, the pre-trial meeting will not Whether a formal trial will evolve into an imitation show for a pre-trial meeting, whether it will involve all the members of the collegial panel, or whether "if some of the members of the collegial panel come to the pre-trial meeting, it is not clear whether the presiding judge or other deciding questions which will participate remains to be answered.

\section{The Legal Effect of Pretrial Conference in China}

Due to the lack of specific legal provisions on the legal effect of pre-trial meetings in the Criminal Procedure Law of China, it brings a lot of inconvenience to judicial practice. On the one hand, we do not know whether the decision reached by the prosecutor and the defender in the pre-trial meeting is valid or not, and the law does not provide for it, so how can a non-legally mandatory agreement be binding, and in formal court proceedings, the agreement will be like How can we guarantee the credibility of the legal agreement and the pretrial meeting if Zhang Feizhi is overthrown? On the other hand, the activities of the pre-trial meeting will be written down by the clerk, and then signed by the judge and the clerk, while the prosecution and the defense do not sign on the record. Without the signature, the pre-trial meeting can draw a corresponding conclusion. If the prosecution and the defense are unwilling to accept the conclusion, what is the future? The path can be appealed, and these laws are not regulated.

The reason lies in the fact that the legal effect of our country's pre-trial meeting has not been affirmed. Just as the law stipulates, the pre-trial meeting is only used by judges to listen to opinions and understand the situation. What is the compulsory force of the "meeting"? The pre-trial meeting is not a necessary procedure but a formal one. Pre-trial preparatory procedure, so the pre-trial meeting cannot solve substantive issues, conviction, sentencing and other issues must be resolved in a formal trial. At the same time, the decision made in the pre-trial meeting is signed by the judge and the clerk. To some extent, the decision of the pre-trial meeting, once confirmed by the signature, should be legally valid. "In the absence of previous circumstances, will the corresponding conclusion be drawn, even if the corresponding conclusion is binding on both sides of terrorism or not?" Clear. " However, since the pre-trial meeting is only a pre-trial preparatory procedure, as mentioned above, the conclusion it has established can easily be overturned or denied in a formal trial because the prosecution and the defence have no right to sign the transcript. In the actual operation process, the effective consensus of the pre-trial meeting cannot only make the formal trial more smoothly, but also the judge can better grasp the evidence of the prosecution and the defense, the defender can also grasp more information in the pre-trial meeting in favor of the defendant, and make adequate preparations for the subsequent trial. The former law does not stipulate the validity of the agreement reached in the pretrial meeting, so it brings a lot of trouble to the recognition of the pre-trial meeting, and will greatly affect the normal conduct of the trial. The result is that the pre-trial meeting becomes an indispensable form, and in the long run the pretrial meeting will lose its significance.

\section{Illegal Evidence Can Be Excluded from Pretrial Meetings or Not}

"The judges may organize the prosecution and defense parties to conduct evidence in the pretrial meeting system." There have been two perspectives on whether illegal evidence can be excluded from pre-trial meetings. One is that illegal evidence must be excluded from pre-trial meetings, so that it is not necessary to show it again in a formal trial, so as not to affect the quality of the judge's trial and conform to the original intention of the pre-trial meeting. . The other view is contrary, because the orientation of the pre-trial meeting is only to listen to opinions and understand the situation, and the specific decision whether to exclude illegal evidence must be made in formal court proceedings. In my opinion, if we have the opportunity to avoid the illegal evidence to enter the court again, then why don't we solve this problem directly in the pre-court meeting, so that the judge can reduce the pressure of the trial, but also can improve the efficiency of the proceedings? The central content of court trial is to deal with the substantive issues of litigation cases. "Whether a judge, on the basis of hearing the evidence, debate and opinions of both parties, makes a decision on whether the acquisition of certain evidence is unconstitutional and whether the evidence should be prohibited from being used in court." However, the exclusion of illegal evidence is a procedural issue, preferably prior to the entity problem was solved before. If the law allows the defendant or the defendant's defender to bring the issue of illegal evidence into the pre-trial proceedings, is not it a double-handed matter, so we cannot only make full use of this judicial innovation, but also greatly promote the efficiency of trial. However, our country's law does not stipulate whether illegal evidence can be excluded in the pre-trial meeting, which brings great trouble to the subsequent court hearing. "The essence of evidence discovery lies in the provision and mutual disclosure of evidence and information by the prosecution and defense parties."

The exclusion of illegal evidence is an important matter of pretrial meetings and has to be deeply explored. China's law provides that the defense has the right to exclude illegal evidence, but the final decision whether to start the procedure of excluding illegal evidence is still in the court. Although the law stipulates that the judge should inform the litigant that he has the right to apply for the exclusion of illegal evidence in time, in the course of actual implementation, the judge has not fulfilled the obligation in time. If the litigant does not even know whether he has the right to exclude illegal evidence, how can he apply for the exclusion of illegal evidence in time? How can the rights of the parties be protected? Moreover, the new Code of Criminal Procedure stipulates that if a party applies for the 
exclusion of illegal evidence, he or she should provide evidence or clues in a timely manner. In practical judicial practice, the judge will at least require the defendant or defender to bear the burden of proof of the illegal evidence, thus invisibly increasing the burden of proof on the defense. This is obviously contrary to the strict stipulation in the Criminal Procedure Law that the prosecution should bear the burden of proof on the legality of the evidence provided by the public security organs, which is not conducive to the protection of the legitimate rights and interests of the defendant. Therefore, we can find that if the court cannot find or does not have reasonable doubts about the evidence, then the pre-trial meeting will be held. There is no way to convene, and at this time the defendant also has no way of relief, which also caused serious damage to judicial justice.

Moreover, the insufficient presentation of evidence is also a great challenge facing the pre-trial meeting. Because both the prosecution and the defense are afraid of the other side's evidence raid, the evidence they collected will not be fully displayed in the pre-trial meeting, which also leads to the legality of the key evidence in the pre-trial meeting review process. Examination, and the legitimacy of these key evidence has a significant impact on the rights and interests of litigants, and if the legitimacy of these evidence is to be reviewed in a formal trial, not only will increase the pressure of trial, but also caused the waste of judicial resources, so that the pre-trial meeting formalized, which establishes the legal recognition of the pre-trial meeting. The degree has had a great impact.

\section{THE PERfECtion OF THE Pretrial CONFERENCE SYSTEM IN CHINA}

\section{A. Defining the Scope of Application of Pretrial Meetings}

In view of the problems mentioned above, the author puts forward some solutions in this section.

When a case applies summary procedure, because our country's Criminal Procedure Law has expanded the scope of application of summary procedure after amendment, there are many complicated cases in judicial practice, but because the defendant pleaded guilty, and applied summary procedure, but there are still many problems, called a pretrial meeting. In fact, it is necessary to completely exclude the application of pre-trial meeting in summary procedure, which will easily lead to the lack of understanding of the facts of the case and cannot find the procedural problems in the case.

When the defendant has not entrusted a defense lawyer, the defendant because of restrictions on action and lack of professional knowledge, canceling the use of pre-trial meetings to improve the efficiency of litigation is reasonable, but it is also not conducive to the protection of the defendant's legitimate litigation rights, so the author thinks that the two views should be combined when the defendant does not have When entrusting defence counsel, the judge shall appoint defence counsel to participate in the pre-trial meeting for the defendant when he considers it necessary to hold the pre-trial meeting.
When a judge meets the need to hold a pre-trial meeting in the second instance procedure, the author thinks that the pre-trial meeting should be applied, because the original purpose of the law is to improve the efficiency of litigation and ensure fairness and justice, and convening a pre-trial meeting is conducive to the judge to understand the case, is conducive to the conduct of court proceedings, and should not be restricted only. It was held in the first instance.

\section{B. Expanding the Participants in Pretrial Meetings}

The core content of enlarging the participants in the pretrial meeting is that the defendant should be allowed to participate in the pre-trial meeting more clearly. In the relevant judicial interpretation, only the defendant can be notified to participate in the pre-trial meeting, that is to say, the defendant is not required to participate in the pre-trial meeting under normal circumstances, but the pre-trial meeting involves after all. It is the defendant's right of action and defense, and the defendant has a direct relationship, but also a direct impact on the formal trial activities of the defendant's substantive treatment, so if the defendant requests to attend the pre-trial meeting then the court should allow him to attend the pre-trial meeting. In practice, if the defendant has entrusted a defense counsel, the court will generally directly request the defendant to attend the pre-trial meeting, and then consider that since the defendant can express his opinion on behalf of the defendant, then the defendant is asked to attend some of these actions, but we know that although the defender on behalf of the defendant entered. In court defense, if the defendant's lawyer is entrusted by himself or communicates with the defendant closely and smoothly, the defender can defend on behalf of the defendant very well, but a large part of the defendant's lawyers are appointed by the people's court, then it is easy to have communication problems, so the defender can defend on behalf of the defendant. In the pre-trial meeting cannot be very good for the defendant to speak, so the court for the defendant to request to attend the pre-trial meeting should be granted, so as to maximize the protection of the interests of the defendant. As a defender, he should also strengthen his defense responsibility. If the defendant cannot attend the pretrial meeting, the defender should express his opinion on behalf of the defendant's interests.

\section{Clarifying the Legal Effect of Pretrial Meetings}

According to the relevant legal provisions, we can know that holding a pre-court meeting is only to listen to opinions and understand the situation, then we can easily find that the meeting is not mandatory, the agreement reached in the meeting is also easy to be overturned in a formal trial, the pre-court meeting is easy to be formalized, so the author believes that What is the value of the pre-trial meeting system? Therefore, the people's court shall be responsible for formulating a written decision on certain issues reached between the prosecution and the defense in the pre-trial meeting, so that both the prosecution and the defense may sign the decision and affirm its legal validity. In a formal trial, the contents confirmed by the decision shall be adopted directly and the validity of the decision shall be determined accordingly. So that the prosecution, the defense and the 
people's court to attach importance to the holding of the pretrial meeting, seriously take the consensus reached at the pretrial meeting can be better affirmed. If the prosecution and the defense present new evidence at the trial, the court can restart the investigation process and not be rigid in accordance with the decision of the pre-trial meeting. In addition, the decision of the meeting reached by the prosecution and the defense must be made in writing, not in a verbal manner. The decision of the meeting must be signed by the prosecution and the defense in order to make the decision credible. As the defendant, even if he cannot participate in the pre-court meeting, the decision must be made in writing. Decisions should also be signed by the defendant before they become effective because they have a direct interest in the defendant's substantive and procedural rights.

Moreover, we should not exaggerate the effectiveness of the pre-trial meeting. There is a great difference between the pre-trial meeting and the formal trial. In the pre-trial meeting, only procedural matters can be discussed. Judges should also look at the contents of the pre-trial meeting in the way of understanding the situation and listening to opinions. They should not regard the pre-trial meeting as the pre-trial of the court. It is also impossible to discuss any substantive issues related to conviction and sentencing. In practical judicial activities, pre-trial meetings often evolve into pre-trial by judges, even when the prosecutor and the defender want to start a debate in the pre-trial meeting, and the judge has not severely curbed this phenomenon, which has to be made public. Fear, formal trial activities will not be formalized, or pre-trial meetings will be in fact higher than the formal trial, and clear court trial as the center, in addition to strict legal provisions, more importantly, requires judges to improve their own quality, establish the dignity of the trial, and prosecutors and defenders should also be accordingly In accordance with the law as far as possible in the formal court to put forward their views and defense opinions, we must not turn the formal trial into a pretrial meeting imitated show.

\section{Two Steps to Solve the Problem of Excluding Illegal Evidence at Pretrial Meetings}

Exclusion of illegal evidence is an important judicial procedure, which is closely related to the rights of the defendant. In actual judicial activities, the parties are vulnerable to infringement of evidence obtained illegally by the public security organs. If the evidence obtained illegally cannot be excluded before trial, then it will be to a great extent. Influencing judicial notarization and excluding illegal evidence is not a simple job. It needs a rigorous confirmation procedure. However, the author believes that the illegality of evidence cannot be fully confirmed by simply confirming the illegality of evidence in the pre-court meeting or in the formal court hearing, but should be solved by both the precourt meeting and the formal court hearing. . "If the decision of the original meeting is allowed to be overturned in subsequent court proceedings, the pre-court meeting will lose its original meaning."

First, the evidence should be fully displayed in the precourt meeting, and the legitimacy of the evidence to express their views, and "agreed to be expressed in writing." Although according to the relevant legal provisions, the precourt meeting is only to listen to opinions and understand the situation, but the author believes that if illegal evidence cannot In formal pre-trial exclusion, it will greatly affect the conduct of court activities, and even appear in order to examine the legitimacy of evidence and have to adjourn the court halfway, so presenting and demonstrating the legitimacy of evidence in the pre-trial meeting will not only improve the efficiency of trial, but also prevent the prosecution and defense evidence raid.

Secondly, in some complex cases, the legitimacy of a pre-trial meeting cannot be confirmed by inquiring about transcripts, medical examination reports, audio-visual recordings and other evidence, and investigators and witnesses must be required to testify before the formal court proceedings to confirm its legitimacy, because the law clearly stipulates that the pre-trial meeting can only discuss the agenda. Sequencing is not a matter of substance. However, after the discussion in the pre-trial meeting, although it cannot be immediately resolved whether the evidence should be excluded, at least to the subsequent trial to clarify the focus of discussion, to a great extent, to help the judge to clarify the thinking of the case and the focus of the trial, for the effectiveness and impartiality of the case trial has a great positive role.

\section{CONCLUSION}

The system of pretrial meeting originates from the foreign judicial system which is more advanced than the domestic one. It has already adapted to the foreign judicial soil in foreign countries. Compared with the domestic system of pretrial meeting, it is more convenient to implement. The purpose of introducing this system is to absorb and draw lessons from the foreign advanced experience and develop the system with Chinese characteristics. Judicial system, so not only we must quote, but also let this new reform measures in China's soil to take root and to grow flourishing. Since the reform of the judicial system in China has always been biased towards improving the effectiveness of trials, which is directly and closely related to the large population and great judicial pressure in China, the reform of the system of pre-court meetings and the reform of the judicial system in China should not only pay attention to efficiency, but also give consideration to fairness and justice, and improve the quality of trials. I believe that the pretrial conference system will further promote the development of legislation and judicature in China.

\section{REFERENCES}

[1] Bian Jianlin, and Chen Zinan," Problems and Countermeasures in Judicial Practice of the Pre-trial Meeting System", Applicability of Law, No. 10, 2015

[2] Chen Weidong, and Du Lei,"Normative Construction and Institutional Application of the Pre-trial Meeting System”, Zhejiang Social Sciences, No. 11, 2012.

[3] Shi Pengpeng, and Chen Zhennan, "review of pretrial criminal proceedings", Jiangsu Social Sciences, 2014 issue first. 
[4] Wei Hongpu, "The Operational Dilemma and Improvement of China's Pre-trial Meeting System", Chinese Public Prosecutor, No. 5, 2015.

[5] Zhang Xu, "pretrial conference for trial centered promotion", Chinese prosecutor", 2015 seventh issue. 